\title{
Community Engagement in Canadian Health and Social Science Research: Field Reports on Four Studies
}

\author{
Andrew D. Eaton
}

\begin{abstract}
Aвsтract Community engagement is a hallmark of Canadian health and social science research, yet we lack detailed descriptions of pragmatic peer engagement possibilities. People affected by a study's topic can and should actively contribute to design, data collection, intervention delivery, analysis, and dissemination yet the nature and scope of involvement can vary based on context. The shift from academic to community-based research teams, where peers who share participant identities assume a leadership role, may be attributed to the HIV/AIDS response where community co-production of knowledge has been a fundamental component since the epidemic's onset. This article discusses four health and social science studies from a community-based participatory research (CBPR) framework. It synthesizes the strengths and limitations of community engagement across these endeavours to offer lessons learned that may inform future CBPR projects.
\end{abstract}

KEYWoRds community engagement, peer researchers, community-based participatory research, HIV/AIDS, Canada

Community engagement — frequently referred to as community-based participatory research (CBPR) - is now a requirement for many funding streams of health and social science research across jurisdictions, disciplines, and topic areas (Canadian Institutes of Health Research [CIHR], 2016; Eder et al., 2018; Ontario HIV Treatment Network [OHTN], 2016). Yet, research in some health and social science streams continues to be conducted and published with varying levels of community engagement. When people who represent the population under study (e.g., people living with HIV) engage with a research project, they often do so as a 'peer researcher'. If the study involves testing an intervention, peers delivering the intervention may have a role such as 'peer supporter.' There is a corresponding lack of literature detailing pragmatic possibilities to engage peers in exploratory and intervention-based health and social science research (De Weger et al., 2018). The existing literature on CBPR focuses primarily on principles and guidelines (Ward et al., 2018) or CBPR implementation examples in a single study (Brush et al., 2019; Collins et al., 2018; Israel et al., 2010). The purpose of this article is to identify specific contributions and opportunities for community members to contribute to health and social science research. This article does so by synthesizing the strengths and weaknesses of four CBPR studies and discusses lessons learned for future endeavours. 


\section{Process Steps in CBPR}

CBPR projects often proceed in a non-linear fashion; for example, the concept for a study may not be fully determined at the time of grant and ethics application, as initial approvals may be required to consult community members and revise a study during its course (Jenkins et al., 2016). Nonetheless, the steps of traditional health and social science studies still occur in CBPR. These steps are: a) concept development, b) questionnaire development, c) intervention design (if applicable), d) data collection, e) data analysis, and f) dissemination. Careful consideration of how community is engaged and potential pitfalls and problems at each step is important to advance CBPR's aim of equitable engagement of academic and community partners (Gonzalez \& Trickett, 2014; Minkler, 2005; Rhodes et al., 2010).

For concept development, CBPR guidelines recommend an investigator-initiated approach to develop the initial idea for a study into a full concept (Johnson-Shelton etal., 2015). The practical nature of this engagement frequently depends on the researcher's access to the study's population (Hacker, 2013; Tapp et al., 2013; Unertl et al., 2016). Collaborative questionnaire development is a key component of CBPR (Gonzalez \& Trickett, 2014), with unique considerations for different measurements (Garcia et al., 2008; Tremblay et al. 2018). Community input can: a) develop and modify standardized measures (Craig et al., 2017); and b) determine relevant demographic and qualitative questions (Liboro et al., 2018). Involving community members especially those affiliated with direct service organizations — in intervention design improves a study's potential for lasting impact (Dickson-Gomez et al., 2016). Community engagement in intervention design tends to be either: a) designing a new peer-based intervention (DicksonGomez et al., 2016; Newman et al., 2014), b) choosing potentially promising manualized interventions and adapting them for a specific context (Anderson-Lewis et al., 2012; Andrews et al., 2012), or c) recruiting participants and engaging in a participatory process to design the intervention as it is being received (Owens et al., 2011; Pawlowski et al., 2017). The role of peers in data collection is a core and common engagement type in CBPR studies (Israel et al., 2010; Jull et al., 2017). Peer interviewers can make participants feel more comfortable than if an academic researcher with few shared characteristics is questioning them (Bush et al., 2019; Unertl et al., 2016). Data analysis may be the most difficult stage of a CBPR study for academic and peer researchers. Academic researchers have alerted others to lengthening project timelines and difficulty training community members in data analysis (Cashman et al., 2008), while peers have reported analysis as a burdensome and time-intensive task that can feel obtuse (Eaton et al., 2018b). Finally, CBPR models recommend complementing traditional dissemination activities (e.g., peer-reviewed articles and juried conference presentations) with more accessible methods like a community report and video (Chen et al., 2010). A frequent CBPR tension in these steps is that while academic researchers should remove the power differential with peer researchers, community members are in effect staff members paid from a grant (Wallerstein et al., 2019). The employment nature of community engagement is further complicated when peers are research-naïve or have little experience leading studies (Musesengwa \& Chimbari, 2017). Therefore, training and supervision are essential to ensure that community members have the necessary competencies to perform their roles and feel confident (Kaida et al., 2019). 


\section{Methods}

A modified narrative approach was used to describe four CBPR studies that I completed between 2014 and 2019 (Moen, 2006). I focused on cataloguing the strengths and limitations of community engagement as I reviewed my past projects and synthesized the findings against CBPR framework criteria to provide reflection for CBPR researchers as a society with evolving culture and practices. This section details each of the four studies. Community engagement strengths and limitations are synthesized in the following section.
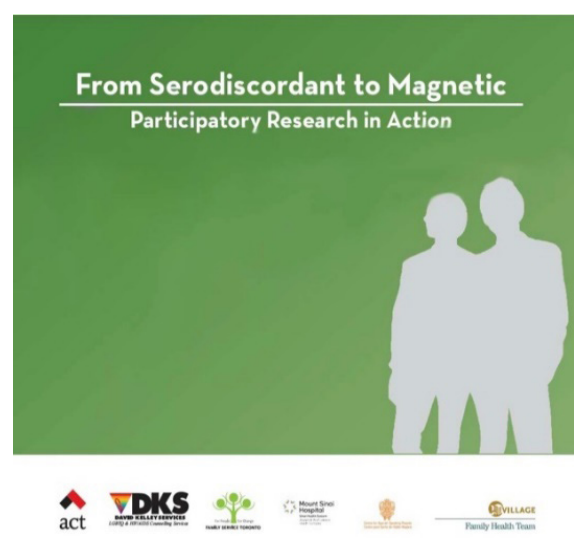

Figure 1. Magnetic Couples study

\section{Magnetic Couples}

This grounded-approach (Strauss \& Corbin, 1994) CBPR study piloted a support group for serodiscordant or, as participants preferred, magnetic couples where one partner is HIV-positive and one partner is HIVnegative (Eaton et al., 2017a). The six recruited couples joined the research team to collaborate on developing an intervention in real-time. Participants attended two planning sessions to determine group content and structure. Throughout the eight-session group that ensued, participants continued to refine the intervention by changing guest speakers, length of session components, and session format. Once the intervention was completed, the entire team of clinician-researchers and participants met for two process evaluation sessions to discuss what worked well about the intervention and what could be improved.

\section{HIV-Associated Neurocognitive Disorder (HAND) \& Social Work}

This sequential mixed-methods study (Morse, 2010) surveyed 108 people affected by HIVassociated neurocognitive disorder, a prevalent aging HIV-related comorbidity, and then interviewed a subset of twenty participants about their history with social work and role of the profession in ameliorating HAND's effects (Eaton et al., 2017b). Four peer researchers aging with HIV, who comprised a 50\% +1 majority of the study team, critiqued and edited the protocol as it was in development. The survey was constructed based on a review of measures, practicebased experience of the clinician-researchers, and lived experience of the peer researchers. Peers recruited survey participants. Once the survey $(n=108)$ was complete, the team used the results to draft relevant qualitative questions for semi-structured interviews with twenty survey participants. This draft questionnaire was then

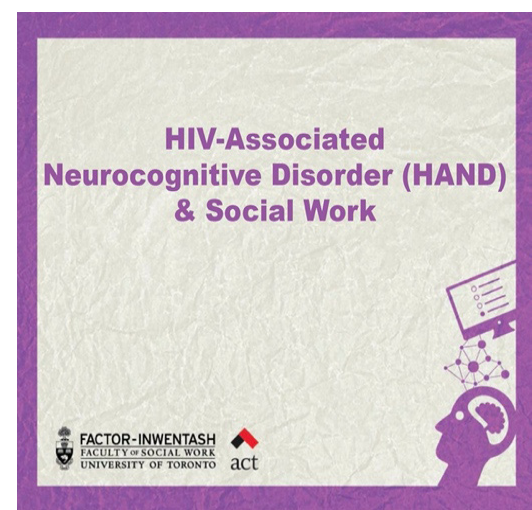

Figure 2. HAND \& Social Work 
tested in data collection training for the peer researchers (Eaton et al., 2018a) and revised based on their feedback of question structure and content. Once all data collection was complete, peers employed thematic coding and then met for an iterative process of discussing codes, determining and verifying themes, noting disagreement, and achieving consensus.

\section{ART of Conversation}

For this project, a critical ethnographic and intervention CBPR approach was utilized (Hodgson, 1999). This pilot study personalized peer intervention to help people living with HIV, who self-identified substance use and antiretroviral therapy (ART, medication that controls HIV) adherence challenges, transition from an acute hospital admission back to community via in-person and phone peer support (Eaton et al., 2019a). People living with HIV provided feedback to the host hospital about the discharge transition and requested peer support (Chan Carusone et al., 2017). Two hospital client engagement sessions followed where seventeen people living with

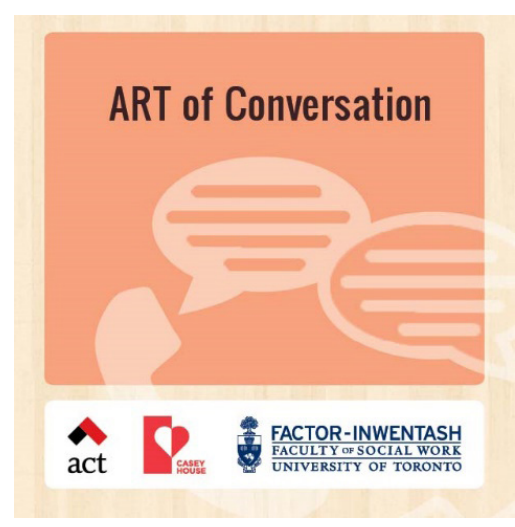

Figure 3. ART of Conversation HIV identified the structure of a post-discharge peer support program, including: duration; content; definition of 'peer supporter;' how peer supporters should be trained; and how the pilot should be evaluated. A group consultation was then held with ten volunteers living with HIV who provide direct service at a partnering community agency. This consultation discussed the requested peer program structure and evaluation methods, including draft questionnaires. A final hospital engagement session $(n=6)$ was facilitated by a peer researcher to continue developing the study questionnaires and intervention details.

Five peer supporters delivered this intervention. These peers completed a total of 44 training hours on relevant skills such as HIV and harm reduction, structuring a phone call, communication tools, and self-care. Five peer researchers, distinct from the peer supporters, attended the training described in HAND \& social work above (Eaton et al., 2018a), with an adaptation for this study's context that involved filmed simulation scenarios changing to reflect topics identified through client consultations such as medication adherence, substance use, and research fatigue (Eaton, 2019). Peer researchers then refined the study questionnaires, collected all data, and conducted analysis.

\section{HAND Randomized Controlled Trial}

This last example is a pilot randomized, controlled trial (RCT) to address HAND through group therapy (Eaton et al., 2019b). The team from the HAND \& social work study expanded to build off the findings and design an intervention study. I identified potential intervention models through key informant interviews with six HAND researchers. A peer researcher and I then held two focus groups with ten people aging with HIV, as well as eight social workers. These consultations finalized trial components including intervention selection, appropriate 
questionnaires, and a sensitive method of data collection. Peers aging with HIV and concerned about cognition were then directly involved in delivery of the trial's intervention arms. Additional peer researchers contributed to content analysis of intervention fidelity.

These projects are part of my overall program of research to develop community-based interventions to address the complexities of living and aging with HIV. As illustrated in Figure 5, I attempt to mitigate such complexities (hospital discharge, cognitive health, and intimate relationships) through the interventions described above. To advance my research program, I assess these studies' results, consider how to adapt, scale, and implement these interventions, and evaluate community engagement. This paper represents a bird's eye view of that community engagement evaluation, where I consider my research program's strengths and limitations, and how my lessons learned can influence the culture of CBPR researchers and investigators considering the use of community engagement techniques in their investigations.

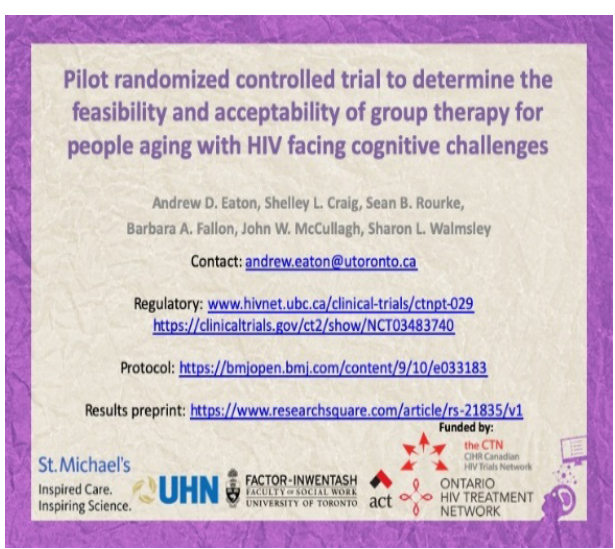

Figure 4. HAND Randomized, controlled trial (RCT)

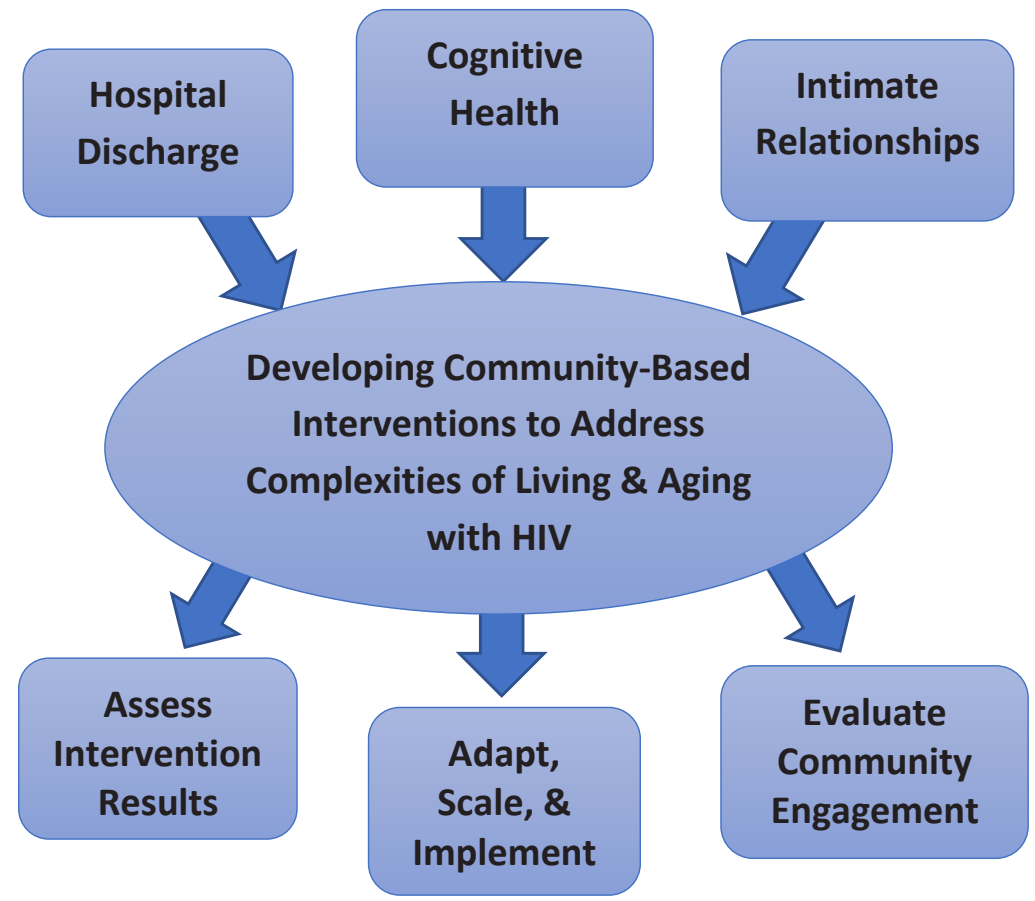

Figure 5. Program of research 


\section{Results}

This section synthesis the various types of engagement of community members on the four studies listed above. Refer to Table 1 for a list of which types of community engagement were employed on each of the four studies. For categories of concept development, questionnaire development, intervention design, data collection, data analysis, and research dissemination, I provide textual descriptions of challenges faced and how these were overcome.

Table 1. Community engagement across four studies

\begin{tabular}{lllll}
\hline Engagement type & $\begin{array}{l}\text { Magnetic } \\
\text { couples }\end{array}$ & $\begin{array}{l}\text { HAND \& } \\
\text { social work }\end{array}$ & $\begin{array}{l}\text { ART of } \\
\text { conversation }\end{array}$ & $\begin{array}{l}\text { HAND } \\
\text { RCT }\end{array}$ \\
\hline Concept development & $\mathrm{X}$ & $\mathrm{X}$ & $\mathrm{X}$ & $\mathrm{X}$ \\
\hline $\begin{array}{l}\text { Questionnaire } \\
\text { development }\end{array}$ & $\mathrm{X}$ & $\mathrm{X}$ & $\mathrm{X}$ & $\mathrm{X}$ \\
\hline Intervention design & $\mathrm{X}$ & $\mathrm{N} / \mathrm{A}$ & $\mathrm{X}$ & $\mathrm{X}$ \\
\hline Data collection & & $\mathrm{X}$ & $\mathrm{X}$ & $\mathrm{X}$ \\
\hline Data analysis & $\mathrm{X}$ & $\mathrm{X}$ & $\mathrm{X}$ & $\mathrm{X}$ \\
\hline Dissemination & $\mathrm{X}$ & $\mathrm{X}$ & $\mathrm{X}$ & $\mathrm{X}$ \\
\hline
\end{tabular}

\section{Concept Development}

The initial idea for all four studies emerged from my social work practice with people living with HIV. With the magnetic couples study, I provided service to clients in serodiscordant relationships who requested couples group support but were hesitant to attend a focus group to design such a group. As such, an anonymous online needs assessment survey was designed and reviewed individually with clients requesting this group. The survey was distributed through my professional networks to obtain insight on the issues (e.g., disclosure, relationship conflict, HIV knowledge) and preferences (e.g., timing, number of sessions) relevant to magnetic couples group therapy. For the other three studies, community members were comfortable self-identifying with the study's population in a group setting. Therefore, client engagement sessions and community-based research team meetings were held to develop the concepts. The benefit and drawback of the online needs assessment is anonymity, where personal input can be made but only at a single timepoint (Hacker, 2013). The risks of community engagement in a study's development are response and performance bias, where the decision to participate and the nature of participation could be biased due to personal relationships with peers (McCambridge et al., 2014). This is arguably an acceptable risk to rigour as communityengaged studies are demonstrably more relevant, sensitive, and sustainable than research that does not involve community members in concept development (Abimbola, 2019; Fekete et al., 2015). 


\section{Questionnaire Development}

The magnetic couples and HAND RCT studies refined existing scales for contextual sensitivity, an example of which is changing heteronormative language to gender-neutral phrasing in a relationship quality measure. HAND \& social work and the ART of conversation determined demographic and qualitative questions based on community input, specifically regarding how best to define the studies' populations and answer the central research questions. A common challenge was community members suggesting questions that may unnecessarily elevate the research risk to participants or that were far afield of the studies' purpose. This challenge is not discussed in CBPR literature, which broadly frames CBPR-developed questionnaires as relevant due to community input (McAllister et al., 2003; Riffin et al., 2016). To address this challenge here, the research team (comprised of a $50 \%+1$ peer researcher majority) voted on questions for inclusion; when a question was excluded, I noted that the suggestion may be addressed in a future endeavour or that the topic could be probed if a participant raised the issue first.

\section{Intervention Design}

Three of the four studies piloted therapeutic interventions, with the goal of assessing their suitability for implementation and/or further study in a larger trial. The ART of conversation designed a new peer program, whereby people living with HIV and who had experience in peer service delivery were consulted on how to structure peer support for HIV and complex needs at the time of discharge from an acute hospital admission.

The HAND RCT engaged people aging with HIV to review numerous intervention types that have shown promise in easing the anxiety and stress of cognitive impairment in the general population. A further step was to consider which model may be best suited to the HIV context. The magnetic couples study recruited six gay male dyadic couples to participate in a multi-session group intervention that they designed as the group progressed. One benefit for community members engaged in these studies was that they could see their contributions leading to a new service being offered (Eaton et al., 2018b). One drawback was that pilot studies are limited in their scope and impact, and the time to broaden implementation can be a source of frustration for peers (Strong et al., 2009).

\section{Data Collection}

Peer researchers conducted all participant interviews on three of the four studies. A lesson learned was the importance of training peers in data collection, which can have reciprocal benefits. Community members feel more confident about the task when adequately trained, and the research instruments undergo pilot-testing through peer researcher simulation of data collection scenarios (Eaton, 2019). The training can help standardize the peer interview experience across multiple interviewers (Eaton et al., 2018a). Other challenges of peer data collection include participants feeling nervous about confidentiality if they share a network with their interviewer (Cené et al., 2015; Lile \& Richards, 2016) and peer researchers feeling burdened by participant contributions (Ibánez-Carrasco et al., 2019). To address participant

Engaged Scholar Journal: Community-Engaged Research, Teaching, and Learning 
nervousness of knowing their interviewer, I obtained consent from all peer researchers to share their name with a participant before the interview; if the participant was uncomfortable with a particular peer researcher, they were matched with a different one. To mitigate peer researcher burden, I was available for debriefs immediately after each interview, had an open-door policy on meeting, and scheduled frequent team meetings where the peer researchers could debrief each other about the interview experience.

In the three studies that used peer interviewing, another common challenge was peers navigating the difference between providing peer support and conducting an interview (Eaton et al., 2018b). This distinction is extraordinarily complex when peers hold multiple roles within their community (Fletcher et al., 2014). Debrief for participants and peer researchers may help ease these challenges. Discussing the dynamics of confidentiality with participants led to more comfort with the security of data (Cené et al., 2015). Regular debriefings between peers and supervisors can help lighten the burden of hearing harrowing stories and negotiate the tension between the service provider, researcher, and community member (Eaton et al., 2018b; Ibáñez-Carrasco et al., 2019).

\section{Data Analysis}

In these studies, peers contributed to analysis by making meaning from in-depth interviews and comparing an intervention's experience to its design and intent (Erlingsson \& Brysiewicz, 2017; Nowell et al., 2017). Misunderstandings and frustrations expressed by peers on the earlier studies led to a change in research team processes for the later studies, where I offered data analysis training and more individual support throughout the process. Despite these attempts at easing the process, community members across all four studies commonly stated that they did not wholly understand the study's findings until they read the first draft of a manuscript. I learned that this first draft can be used as a boundary object to help bridge peer researchers to the concept and conventions of academic publication.

\section{Dissemination}

Whereas data analysis was the biggest hurdle in these four studies, community members regularly stated that engaging in dissemination was their preferred activity. This preference may be attributed to satisfaction with completing a study that peers have been involved in since its initial design and starting to see the impact from the results (Lictveld et al., 2016). In all four studies, community members have co-presented findings and co-authored articles. I found that peers often prefer to present the rationale and implications of a study, sometimes feeling nervous with detailing the methods and results. Frequent meetings and debrief about dissemination activities have eased peers' hesitation in reporting specific components of these studies, as has been found elsewhere (McDavitt et al., 2016).

\section{Summary of Results}

I learned the most from engaging with peer researchers in questionnaire development and data analysis. In developing questionnaires, I realized how much I did not know and had not 
considered the topic and population we were researching through peers identifying essential inquiry areas. In data analysis, I learned how barriers in research could intimidate people. The complex language used in analysis can make the actual process (for example, consolidating a lengthy interview into keywords that can be used as codes and themes and seeing if those keywords are relevant in other interviews) feel difficult and daunting.

Overall, I attempted to bolster strengths and mitigate challenges with community engagement on these four studies through improved training and supervision, greater choice and variety for peers, and considering community members' motivations.

\section{Lessons for Training and Supervision}

While training and supervision are important for CBPR studies, the employment power differential inherent in training and supervision can cause tensions (Devotta et al., 2016). The literature on training community members recommends multi-modal educational design, which was incorporated in these studies (Eaton et al., 2018a; Ibáńez-Carrasco et al., 2019), yet it does not fully address the challenge of simultaneously managing and equitably partnering with peers. Across these studies, I found that introducing self-reflective training and supervision activities helped peers self-identify areas of improvement. These self-reflective activities included filmed simulation — video recording role-play exercises such as interviews that peers could watch and assess their performance (Eaton, 2019), and session reports, where peers could do a written debrief on participant interaction and reflect on successes and challenges.

\section{Lessons on Choice and Variety}

The CBPR literature predominantly defines community engagement as all peers performing the same tasks on a study (Israel et al., 2010; Ward et al., 2018; De Weger et al., 2018). This model was used in the magnetic couples and HAND \& social work studies, and feedback from peers was that there should be more variety and choice. With ART of conversation and the HAND RCT, some peers chose to join the research team, and other peers decided to join the intervention team. Further, peers specified activities of most interest. As an example, some community members only engaged in data analysis on the HAND RCT. Such choice and variety may be a new concept to CBPR models. They may offer engagement possibilities for community members who cannot commit to a full study arc or develop skill with a specific task.

\section{Lessons on Motivation}

All community members were financially compensated. Interestingly, post-study interviews with the peer researchers on these studies found that payment was appreciated but not a critical motivating factor to remain engaged (Eaton et al., 2018b). This aligns with existing research on motivations for work (Sachau, 2007; Tesavrita \& Suryadi, 2012), including for peers (BassetJones \& Lloyd, 2005). Instead, the key motivating factors were personal interest in the topic, feeling like leaders in one's community, and a supportive work environment (adequate training and supervision) that motivated peer researchers to continue engaging with these studies. The 
focus on these factors may explain why many of the peers on these studies continued to engage across multiple (including all four) of the endeavours.

\section{Conclusion}

This article highlights how I adapted community engagement approaches across four CBPR studies. This work's recommendations are targeted to academic researchers, peer researchers, patients, practitioners, and policymakers.

For researchers such as myself — both engaged in CBPR and looking to start engaging community in research — developing a supportive work environment of thoughtful training and supervision alongside choice and variety and consideration of motivations beyond compensation are the key takeaways for successful community engagement in this context. Being receptive to feedback and adaptive to change during a study's course is already a key component of CBPR. This article contributes reflecting on numerous initiatives within a broad program of research, considering how to incorporate lessons learned across multiple studies.

For peer researchers, these four projects have demonstrated that peer researchers have gained aptitude in conducting research, presenting findings, and generating new models of care and support for their peers. Peer researchers on these studies contributed great insight into their population's strengths and needs, preferred language, and intervention format and content preferences. These contributions make intervention research a better science that is more relevant and attuned to community context and culture.

For patients seeking support, it is crucial to look for intervention programs derived from CBPR. While community engagement is no guarantee that an intervention will meet your needs - as people are diverse even within highly specific subgroups — a CBPR process offers some promise that an intervention was designed in partnership with your peers and that it may be more sensitive and relevant than an intervention solely constructed by researchers and practitioners. Asking an organization about the amount and quality of community engagement in an intervention's design can be essential in determining whether their services would be helpful.

For practitioners, of which I was a practicing social worker during all of these studies, this paper demonstrates that your practice can permit you to lead research efforts that simultaneously engage community and achieve organizational priorities. Using practice to inform research can allow you to collaborate with community leaders to pilot and implement new models of care in a method that may be sustainable and adaptable.

For policymakers, this type of work is possible when research funders allow applications from practitioners in hospitals and non-profit organizations - who may not have an academic appointment - and when such applicants prioritize community members' collaboration. Broadening application requirements to be accessible for researchers beyond post-secondary institutions means that research can be conducted in an applied manner that may have more significant potential for local implementation and impact, on a more efficient timeline than translating purely academic research to actual practice. 
This work is not without limitations. In this paper, I present my evaluation of four projects where I was the principal investigator (HAND \& Social Work, ART of Conversation, HAND RCT) or a key co-investigator in the research initiation and implementation (Magnetic Couples). The risk of confirmation bias cannot be ruled out. Also, I presented this analysis through my lens as a cisgender male heterosexual Caucasian middle-class settler who has the privileges and supports (such as from senior researchers) to apply for my grants, first as a social worker in practice and now as an early-career researcher in academia. Further CBPR practitioners may have other interpretations of the strengths and limitations of this work.

Further research evaluating peer researchers' meaningful involvement in CBPR in the context of health and social science studies could explore impacts of community engagement on a study's uptake and peer researcher experiences over a lengthy period of concentration on multiple studies.

\section{Acknowledgements}

This work was supported by community-based research grants \#1043 and G1074 from the Ontario HIV Treatment Network (OHTN), award \#387721 from the Canadian Institutes of Health Research (CIHR), and pilot study grant \#PT029 from the CIHR Canadian HIV Trials Network (CTN). ADE's salary is supported by Endgame Leader Award \#1100 from the OHTN. Projects reported in this article received ethics approval from the University of Toronto's HIV/AIDS Research Ethics Board (\#29715, 31509, 34124, 35860), Toronto's Mount Sinai Hospital Research Ethics Board (No. 13-0036-E), and St. Michael's Hospital Research Ethics Board (\#17-334).

\section{About the Author}

Andrew D. Eaton is a Ph.D. Candidate and Research Director at the Factor-Inwentash Faculty of Social Work at the University of Toronto. He is a cisgender male heterosexual Caucasian, middle-class settler. He is the Ontario HIV Treatment Network's (OHTN) Endgame Student Leader in HIV-Associated Neurocognitive Disorder and Psychosocial Interventions. Email: andrew.eaton@utoronto.ca 


\section{References}

Abimbola, S. (2019). Beyond positive a priori bias: Reframing community engagement in LMICs. Health Promotion International, 35(3), 598-609. https://doi.org/10.1093/heapro/daz023

Anderson-Lewis, C., Cuy-Castellanos, D., Byrd, A., Zynda, K., Sample, A., Blakely Reed, V., Beard, M., Minor, L., \& Yadrick, K. (2012). Using mixed methods to measure the perception of community capacity in an academic-community partnership for a walking intervention. Health Promotion Practice, 13(6), 788-796. https://doi.org/10.1177/1524839911404230

Andrews, J. O., Tingen, M. S., Jarriel, S. C., Caleb, M., Simmons, A., Brunson, J., Mueller, M., Ahluwalia, J. S., Newman, S. D., Cox, M. J., Magwood, G., \& Hurman, C. (2012).

Application of a CBPR framework to inform a multi-level tobacco cessation intervention in public housing neighborhoods. American Journal of Community Psychology, 50(1-2), 129-140. https://doi.org/10.1007/s10464-011-9482-6

Bassett-Jones, N., \& Lloyd, G. C. (2005). Does Herzberg's motivation theory have staying power? Journal of Management Development, 24(10), 929-943. https://doi. org/10.1108/02621710510627064

Brush, B.L., Mentz, G., Jensen, M., Jacobs, B., Saylor, K.M., Rowe, Z., Israel, B.A. \& Lachance, L. (2019). Success in long-standing community-based participatory research (CBPR) partnerships: A scoping literature review. Health Education \& Behavior, 47(4), 556-568. https://doi.org/10.1177/1090198119882989

Bush, E. J., Singh, R. L., \& Kooienga, S. (2019). Lived experiences of a community: Merging interpretive phenomenology and community-based participatory research. International Journal of Qualitative Methods, 18. https://doi.org/10.1177/1609406919875891

Canadian Institutes of Health Research (CIHR). (2016). CIHR HIVIAIDS community-based research. Retrieved from www.cihr-irsc.gc.ca/e/25835.html

Cashman, S. B., Adeky, S., Allen, A. J., 3rd, Corburn, J., Israel, B. A., Montano, J., Rafelito, A., Rhodes, S. D., Swanston, S., Wallerstein, N., \& Eng, E. (2008). The power and the promise: Working with communities to analyze data, interpret findings, and get to outcomes. American Journal of Public Health, 98(8), 1407-1417. https://doi.org/10.2105/ AJPH.2007.113571

Cene, C. W., Haymore, L. B., Enga, Z., Sallah, S. H., Ritchwood, T., Wynn, M., Ellis, D., \& Corbie-Smith, G. (2015). Data collection and management in community-engaged research: Lessons learned from two community-based participatory research partnerships. Progress in Community Health Partnerships: Research, Education, and Action, 9(3), 413-422. https://doi. org/10.1353/cpr.2015.0057

Chan Carusone, S., O'Leary, B., McWatt, S., Stewart, A., Craig, S. L., \& Brennan, D. J. (2017). The lived experience of the hospital discharge "plan": A longitudinal qualitative study of complex patients. Journal of Hospital Medicine, 12(1), 5-10. https://doi.org/10.1002/jhm.2671

Chen, P. G., Diaz, N., Lucas, G., \& Rosenthal, M. S. (2010). Dissemination of results in community-based participatory research. American Journal of Preventive Medicine, 39(4), 372-378. https://doi.org/10.1016/j.amepre.2010.05.021 
Collins, S.E., Clifasefi, S.L., Stanton, J., Straits, K.J., Gil-Kashiwabara, E., Rodriguez Espinosa, P., Nicasio, A.V., Andrasik, M.P., Hawes, S.M., Miller, K.A. \& Nelson, L.A. (2018). Community-based participatory research (CBPR): Towards equitable involvement of community in psychology research. American Psychologist, 73(7), 884-898. https://doi.org/ 10.1037/amp0000167

Craig, S. L., McInroy, L. B., D’Souza, S., Austin, A., McCready, L. T., Eaton, A. D., Shade, L. R., \& Wagaman, M. A. (2017). Influence of information and communication technologies on the resilience and coping of sexual and gender minority youth in the United States and Canada (Project \#Queery): Mixed methods survey. JMIR Research Protocols, 6(9), e189. https://doi. org/10.2196/resprot.8397

De Weger, E., Van Vooren, N., Luijkx, K. G., Baan, C. A., \& Drewes, H. W. (2018). Achieving successful community engagement: a rapid realist review. BMC Health Services Research, 18(1), 285. https://doi.org/10.1186/s12913-018-3090-1

Devotta, K., Woodhall-Melnik, J., Pedersen, C., Wendaferew, A., Dowbor, T. P., Guilcher, S. J., Hamilton-Wright, S., Ferentzy, P., Hwang, S. W., \& Matheson, F. I. (2016). Enriching qualitative research by engaging peer interviewers: A case study. Qualitative Research, 16(6), 661-680. https://doi.org/10.1177/1468794115626244

Dickson-Gomez, J., Corbett, A. M., Bodnar, G., Zuniga, M. O., Guevara, C. E., Rodriguez, K., \& Navas, V. (2016). Context and group dynamics in a CBPR-developed HIV prevention intervention. Health Promotion International, 31(1), 93-105. https://doi.org/10.1093/heapro/ dau058

Eaton, A. D. (2019). Filmed simulation to train peer researchers in community-based participatory research. Social Work Research, 43(3), 195-199. https://academic.oup.com/swr/articleabstract/43/3/195/5550914

Eaton, A. D., Cattaneo, J. S., Watchorn, J. M., Bilbao-Joseph, C., Bowler, S., Hazelton, M., Myslik, J., Ross, A., \& Chambers, L. (2017a). From serodiscordant to magnetic: The feasibility and acceptability of a pilot psychoeducational group intervention designed to improve relationship quality. Social Work with Groups, 41(4), 323-335. https://doi.org/10.1080/0160 9513.2017 .1369922

Eaton, A. D., Chan Carusone, S., Craig, S. L., Telegdi, E., McCullagh, J. W., McClure, D., Wilson, W., Zuniga, L., Berney, K., Ginocchio, G. F., Wells, G. A., Montess, M., Busch, A., Boyce, N., Strike, C., \& Stewart, A. (2019a). The ART of conversation: Feasibility and acceptability of a pilot peer intervention to help transition complex HIV-positive people from hospital to community. BMJ Open, 9(3), e026674. https://doi.org/10.1136/bmjopen-2018-026674

Eaton, A. D., Craig, S. L., \& Wallace, R. (2017b). The intersecting cognitive and aging needs of HIV-positive older adults: Implications for social work practice. Social Work in Health Care, 56(8), 733-747. https://doi.org/10.1080/00981389.2017.1339759

Eaton, A. D., Ibáńez-Carrasco, F., Craig, S. L., Carusone, S. C., Montess, M., Wells, G. A., \& Ginocchio, G. F. (2018a). A blended learning curriculum for training peer researchers to conduct community-based participatory research. Action Learning: Research and Practice, 15(2), 139-150. https://doi.org/10.1080/14767333.2018.1462143 
Eaton, A. D., Tsang, A. K. T., Craig, S. L., \& Ginocchio, G. F. (2018b). Peer researchers in post-professional healthcare: A glimpse at motivations and partial objectivity as opportunities for action researchers. Action Research, 17(4), 591-609. https://doi. org/10.1177/1476750318811913

Eaton, A. D., Walmsley, S. L., Craig, S. L., Rourke, S. B., Sota, T., McCullagh, J. W., \& Fallon, B. A. (2019b). Protocol for a pilot randomised controlled trial evaluating feasibility and acceptability of cognitive remediation group therapy compared with mutual aid group therapy for people ageing with HIV-associated neurocognitive disorder (HAND) in Toronto, Canada. BMJ Open, 9(10), e033183. https://doi.org/10.1136/bmjopen-2019-033183

Eder, M. M., Evans, E., Funes, M., Hong, H., Reuter, K., Ahmed, S., Calhoun, K., Corbie-Smith, G., Dave, G., DeFino, M., Harwood, E., Kissack, A., Kleinman, L. C., \& Wallerstein, N. (2018). Defining and measuring community engagement and community-engaged research: Clinical and translational science institutional practices. Progress in Community Health Partnerships: Research, Education, and Action, 12(2), 145-156.

Erlingsson, C., \& Brysiewicz, P. (2017). A hands-on guide to doing content analysis. African Journal of Emergency Medicine, 7(3), 93-99. https://doi.org/10.1016/j.afjem.2017.08.001

Fekete, C., Segerer, W., Gemperli, A., Brinkhof, M. W., \& Swi, S. C. I. S. G. (2015). Participation rates, response bias and response behaviours in the community survey of the Swiss Spinal Cord Injury Cohort Study (SwiSCI). BMC Medical Research Methodology, 15(1), 80. https:// doi.org/10.1186/s12874-015-0076-0

Fletcher, F., Hammer, B., \& Hibbert, A. (2014). "We know we are doing something good, but what is it?": The challenge of negotiating between service delivery and research in a CBPR project. Journal of Community Engagement and Scholarship, 7(2). https://digitalcommons. northgeorgia.edu/jces/vol7/iss $2 / 3$

Garcia, C. M., Gilchrist, L., Campesino, C., Raymond, N., Naughton, S., \& de Patino, J. G. (2008). Using community-based participatory research to develop a bilingual mental health survey for Latinos. Progress in Community Health Partnerships: Research, Education, and Action, 2(2), 105-120. https://doi.org/10.1353/cpr.0.0011

Gonzalez, J., \& Trickett, E. J. (2014). Collaborative measurement development as a tool in CBPR: Measurement development and adaptation within the cultures of communities. American Journal of Community Psychology, 54(1-2), 112-124. https://doi.org/10.1007/s10464-014$9655-1$

Hacker, K. (2013). Community-based participatory research. Sage.

Hodgson, D. L. (1999). Critical interventions: Dilemmas of accountability in contemporary ethnographic research. Identities Global Studies in Culture and Power, 6(2-3), 201-224. https://doi.org/10.1080/1070289X.1999.9962643

Ibáñez-Carrasco, F., Watson, J. R., \& Tavares, J. (2019). Supporting peer researchers: Recommendations from our lived experience/expertise in community-based research in Canada. Harm Reduction Journal, 16(1), 55. https://doi.org/10.1186/s12954-019-0322-6

Israel, B. A., Coombe, C. M., Cheezum, R. R., Schulz, A. J., McGranaghan, R. J., Lichtenstein, R., Reyes, A. G., Clement, J., \& Burris, A. (2010, Nov). Community-based participatory research: a capacity-building approach for policy advocacy aimed at eliminating health disparities. American Journal of Public Health, 100(11), 2094-2102. https://doi.org/10.2105/ AJPH.2009.170506 
Jenkins, E. K., Kothari, A., Bungay, V., Johnson, J. L., \& Oliffe, J. L. (2016). Strengthening population health interventions: Developing the CollaboraKTion framework for community-based knowledge translation. Health Research Policy and Systems, 14(1), 65. https://doi.org/10.1186/s12961-016-0138-8

Johnson-Shelton, D., Moreno-Black, G., Evers, C., \& Zwink, N. (2015). A community-based participatory research approach for preventing childhood obesity: The communities and schools together project. Progress in Community Health Partnerships: Research, Education, and Action, 9(3), 351-361. https://doi.org/10.1353/cpr.2015.0056

Jull, J., Giles, A., \& Graham, I. D. (2017). Community-based participatory research and integrated knowledge translation: Advancing the co-creation of knowledge. Implementation Science, 12(1), 150. https://doi.org/10.1186/s13012-017-0696-3

Kaida, A., Carter, A., Nicholson, V., Lemay, J., O’Brien, N., Greene, S., Tharao, W., Proulx-Boucher, K., Gormley, R., Benoit, A., Bernier, M., Thomas-Pavanel, J., Lewis, J., de Pokomandy, A., Loutfy, M., Abdul-Noor, R., Anema, A., Angel, J., Bakombo, D. M., ... \& Zhu, J. L. (2019). Hiring, training, and supporting peer research associates: Operationalizing community-based research principles within epidemiological studies by, with, and for women living with HIV. Harm Reduction Journal, 16(1), 47. https://doi.org/10.1186/s12954-0190309-3

Liboro, R. M., Ibáńez-Carrasco, F., Rourke, S. B., Eaton, A. D., Medina, C., Pugh, D., Rae, A., Ross, L. E., \& Shuper, P. A. (2018). Barriers to addressing HIV-associated neurocognitive disorder (HAND): Community-based service provider perspectives. Journal of HIVIAIDS \& Social Services, 17(3), 209-223. https://doi.org/10.1080/15381501.2018.1431168

Lichtveld, M., Kennedy, S., Krouse, R. Z., Grimsley, F., El-Dahr, J., Bordelon, K., Sterling, Y., White, L., Barlow, N., DeGruy, S., Paul, D., Denham, S., Hayes, C., Sanders, M., Mvula, M. M., Thornton, E., Chulada, P., Mitchell, H., Martin, W. J., 2nd, Stephens, K. U., \& Cohn, R. D. (2016). From design to dissemination: Implementing community-based participatory research in postdisaster communities. American Journal of Public Health, 106(7), 1235-1242. https://doi.org/10.2105/AJPH.2016.303169

Lile, J., \& Richards, L. (2016). Youth as interviewers: Methods and findings of participatory peer interviews in a youth garden project. Journal of Adolescent Research, 33(4), 496-519. https:// doi.org/10.1177/0743558416670009

McAllister, C. L., Green, B. L., Terry, M. A., Herman, V., \& Mulvey, L. (2003). Parents, practitioners, and researchers: Community-based participatory research with early head start. American Journal of Public Health, 93(10), 1672-1679. https://doi.org/10.2105/ ajph.93.10.1672

McCambridge, J., Witton, J., \& Elbourne, D. R. (2014). Systematic review of the Hawthorne effect: New concepts are needed to study research participation effects. Journal of Clinical Epidemiology, 67(3), 267-277. https://doi.org/10.1016/j.jclinepi.2013.08.015

McDavitt, B., Bogart, L., Mutchler, M., Wagner, G., Green, H. J., Lawrence, S., Mutepfa, K., \& Nogg, K. (2016). Dissemination as dialogue: Building trust and sharing research findings through community engagement. Preventing Chronic Disease, 13. https://doi.org/10.5888/ $\operatorname{pcd} 13.150473$

Minkler, M. (2005). Community-based research partnerships: challenges and opportunities. Journal of Urban Health, 82(2), ii3-ii12. https://doi.org/10.1093/jurban/jti034

Engaged Scholar Journal: Community-Engaged Research, Teaching, and Learning 
Moen, T. (2006). Reflections on the narrative research approach. International Journal of Qualitative Methods, 5(4), 56-69. https:doi.org/10.1177/160940690600500405

Morse, J. M. (2010). Simultaneous and sequential qualitative mixed method designs. Qualitative Inquiry, 16(6), 483-491. https://doi.org/10.1177/1077800410364741

Musesengwa, R., \& Chimbari, M. J. (2017). Experiences of community members and researchers on community engagement in an Ecohealth project in South Africa and Zimbabwe. BMC Medical Ethics, 18(1), 76. https://doi.org/10.1186/s12910-017-0236-3

Newman, S. D., Gillenwater, G., Toatley, S., Rodgers, M. D., Todd, N., Epperly, D., \& Andrews, J. O. (2014). A community-based participatory research approach to the development of a Peer Navigator health promotion intervention for people with spinal cord injury. Disability and health journal, 7(4), 478-484. https://doi.org/10.1016/j.dhjo.2014.04.006

Nowell, L. S., Norris, J. M., White, D. E., \& Moules, N. J. (2017). Thematic analysis: Striving to meet the trustworthiness criteria. International Journal of Qualitative Methods, 16(1). https:// doi.org/10.1177/1609406917733847

Ontario HIV Treatment Network (OHTN). (2016). Funding guidelines: OHTN community-based research and evaluation fund. Retrieved from www.ohtn.on.ca/wp-content/uploads/2016/01/ OHTN-CBR-And-Evaluation-Guidelines-January-2016.pdf

Owens, C., Farrand, P., Darvill, R., Emmens, T., Hewis, E., \& Aitken, P. (2011). Involving service users in intervention design: A participatory approach to developing a text-messaging intervention to reduce repetition of self-harm. Health Expectations, 14(3), 285-295. https:// doi.org/10.1111/j.1369-7625.2010.00623.x

Pawlowski, C. S., Winge, L., Carroll, S., Schmidt, T., Wagner, A. M., Nortoft, K. P. J., Lamm, B., Kural, R., Schipperijn, J., \& Troelsen, J. (2017). Move the neighbourhood: Study design of a community-based participatory public open space intervention in a Danish deprived neighbourhood to promote active living. BMC Public Health, 17(1), 481. https://doi. org/10.1186/s12889-017-4423-4

Rhodes, S. D., Malow, R. M., \& Jolly, C. (2010). Community-based participatory research: A new and not-so-new approach to HIV/AIDS prevention, care, and treatment. AIDS Education and Prevention, 22(3), 173-183. https://doi.org/10.1521/aeap.2010.22.3.173

Riffin, C., Kenien, C., Ghesquiere, A., Dorime, A., Villanueva, C., Gardner, D., Callahan, J., Capezuti, E., \& Reid, M. C. (2016). Community-based participatory research: understanding a promising approach to addressing knowledge gaps in palliative care. Annals of Palliative Medicine, 5(3), 218-224. https://doi.org/10.21037/apm.2016.05.03

Sachau, D. (2007). Resurrecting the motivation-hygiene theory: Herzberg and the positive psychology movement. Human Resource Development Review, 6(4), 377-393. https://doi. org/10.1177/1534484307307546

Strauss, A., \& Corbin, J. (1994). Grounded theory methodology: An overview. In N. Denzin \& Y. Lincoln (Eds.), Handbook of qualitative research ( ${ }^{\text {st }}$ ed., pp. 273-284). Sage.

Strong, L. L., Israel, B. A., Schulz, A. J., Reyes, A., Rowe, Z., Weir, S. S., \& Poe, C. (2009). Piloting interventions within a community-based participatory research framework: Lessons learned from the healthy environments partnership. Progress in Community Health Partnerships: Research, Education, and Action, 3(4), 327-334. https://doi.org/10.1353/cpr.0.0094 
Tapp, H., White, L., Steuerwald, M., \& Dulin, M. (2013). Use of community-based participatory research in primary care to improve healthcare outcomes and disparities in care. Journal of Comparative Effectiveness Research, 2(4), 405-419. https://doi.org/10.2217/cer.13.45

Tesavrita, C., \& Suryadi, D. (2012). Identification of Herzberg's motivator-hygiene factors for SME's workers: Case study of SME in Bandung, Indonesia. Procedia Economics and Finance, 4, 299303. https://doi.org/10.1016/S2212-5671(12)00344-9

Tremblay, M. C., Martin, D. H., McComber, A. M., McGregor, A., \& Macaulay, A. C. (2018). Understanding community-based participatory research through a social movement framework: A case study of the Kahnawake Schools Diabetes Prevention Project. BMC Public Health, 18(1), 487. https://doi.org/10.1186/s12889-018-5412-y

Unertl, K. M., Schaefbauer, C. L., Campbell, T. R., Senteio, C., Siek, K. A., Bakken, S., \& Veinot, T. C. (2016). Integrating community-based participatory research and informatics approaches to improve the engagement and health of underserved populations. Journal of the American Medical Informatics Association, 23(1), 60-73. https://doi.org/10.1093/jamia/ocv094

Wallerstein, N. B., \& Duran, B. (2006). Using community-based participatory research to address health disparities. Health Promotion Practice, 7(3), 312-323. https://doi. org/10.1177/1524839906289376

Ward, M., Schulz, A. J., Israel, B. A., Rice, K., Martenies, S. E., \& Markarian, E. (2018). A conceptual framework for evaluating health equity promotion within community-based participatory research partnerships. Evaluation and Program Planning, 70, 25-34. https://doi. org/10.1016/j.evalprogplan.2018.04.014 